\title{
Efficacy of the main repellents available in the Brazilian market against Aedes aegypti bites under concentrations applied to pediatric populations
}

\author{
Bruna Oliveira da Silva ${ }^{[1]}$, Thainá Oliveira Felicio Olivatti ${ }^{[1]}$, Rafael Guimarães Kanda ${ }^{[1]}$, \\ Gustavo Noé de Marco ${ }^{[1]}$, Felipe José Santaella ${ }^{[1]}$, Newton Goulart Madeira ${ }^{[2]}$, \\ Vidal Haddad Junior ${ }^{[1]}$ and Hélio Amante Miot ${ }^{[1]}$
}

[1]. Departamento de Dermatologia e Radioterapia, Faculdade de Medicina de Botucatu, Universidade Estadual Paulista, Botucatu, SP, Brasil.

[2]. Departamento de Parasitologia, Instituto de Biociências, Universidade Estadual Paulista, Botucatu, SP, Brasil.

\section{Dear Editor:}

Mosquitoes are the most important vectors of infectious diseases in the world, and currently in Brazil, there are endemic areas of viruses such as dengue, zika, chikungunya, and yellow fever, besides malaria and leishmaniasis, which require public health actions, such as control of breeding sites and use of insecticides and repellents ${ }^{1}$.

Insect repellents are aimed at avoiding bites, and their efficacy depends, in addition to the concentration of the active components, on elements related to the insect and the user, such as sweat, temperature, eczema, or areas with higher insect density. They can be applied topically on the skin, clothing, or on mosquito nets. Its adoption as a prevention strategy promoted reduction in malaria-associated mortality in China and Africa, as well as cutaneous leishmaniasis infection in South America and the Middle East ${ }^{2-4}$. However, children are restricted to certain products or concentrations, according to age, making them susceptible to illness ${ }^{5}$.

N,N-Diethyl-3-methylbenzamide (DEET) at a concentration of $30-50 \%$ is the best known repellent substance; however, its administration is limited by toxicity and skin irritation, contraindicating it in children younger than 10 years. Lower concentrations (10-30\%) are, however, present in pediatric products ${ }^{6}$.

Icaridin at a concentration of $20-25 \%$ is a compound derived from piperidine, found in black pepper (Piper nigrum). It is highly effective, with a low rate of sensitization and is safe to use in children older than 2 years of age; however, studies have not been conducted in pregnant women ${ }^{5-7}$.

Corresponding author: Prof. Hélio Amante Miot

e-mail: heliomiot@fmb.unesp.br

Received 25 November 2017

Accepted 28 March 2018
Insect repellents with $I R 3535 \AA$ at a concentration of $10-20 \%$ has synthetic origins, and is considered safe to use from 6 months of age $\mathrm{a}^{5-7}$.

\section{Ethical considerations}

This study aimed to evaluate the efficacy of the main pediatric repellents marketed in Brazil against Aedes aegypti (Table 1). The project was approved by the institution's ethics committee and proceeded between February and April 2017 (CEP 135/08).

The experiment was carried out by 5 healthy adults who exposed their forearms to 30 healthy adult females $A$. aegypti (Rockfeller strain) retained on transparent plastic beds treated with 5\% glucose solution and submitted for fasting blood feeding for 24 hours $^{8}$. The mosquito breeding laboratory included temperature, humidity, and illumination control to standardize the experimental conditions, being maintained by the Department of Parasitology, Instituto de Biociências, Universidade Estadual Paulista (IBB-UNESP), Botucatu-SP.

The time (in seconds) of the exposure to the first mosquito bite in each forearm without products and with bilateral combinations of the main Brazilian commercial repellents with pediatric indications was measured. Each experiment, therefore, resulted in three measures ${ }^{8}$.

The forearms were exposed to groups of 30 mosquitoes for a period of $60 \mathrm{~s}$. If no bites occurred, the forearm was removed from the cage for $540 \mathrm{~s}(9 \mathrm{~min})$ and then, reintroduced. For the standardization of the exposed areas, the hands of the volunteers were protected by latex gloves. If no bites occurred, the study was interrupted in 10,800 s (3h). Mosquitos were replaced if necessary (in cases of death, flight, or loss of vitality) ${ }^{8}$. Data normality was assessed using the Shapiro-Wilk test ${ }^{9}$. Bilateral comparative analysis was performed using a generalized linear model of mixed effects and two-tailed $\mathrm{p}$ values $<0.05$ were considered significant. Multiple comparisons were corrected by the Sidak procedure. 
TABLE 1: Times until the first bite in the forearms with the different products tested $(n=90)$.

\begin{tabular}{lc}
\hline Product & Time to first bite: mean (SD) in seconds \\
\hline IR3535 30\% & $10,400(1,041)^{\mathrm{a}, \mathrm{b}, \mathrm{c}}$ \\
Icaridin $25 \%$ & $8,871(2,531)^{\mathrm{a}, \mathrm{b}, \mathrm{c}}$ \\
IR3535 12.5\%+ botanical extracts* & $7,553(2,809)^{\mathrm{a}}$ \\
DEET 7.1\% & $6,447(2,134)^{\mathrm{a}}$ \\
Nude forearm & $23(11)$ \\
\hline
\end{tabular}

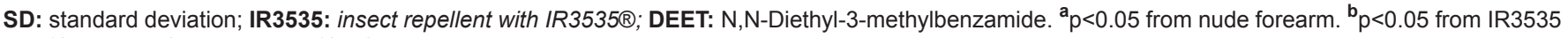
$12.5 \%$. ${ }^{c} p<0.05$ from DEET $7.1 \%$. ${ }^{*}$ Clove, citronella, cinnamon, nutmeg and bergamot.

Thirty contralateral experiments (90 measurements) were recorded. There were no systemic adverse effects in the volunteers ${ }^{10}$.

The mean times to the bites in the forearms was greater for $30 \%$ IR3535 and $25 \%$ icaridin (Table 1).

An ideal insect repellent has not yet been developed and its characteristics would involve the absence of toxicity, irritations, absorption, and odor; biodegradability; lack of effect on the ozone layer; insecticide properties; safety during childhood and pregnancy; a broad spectrum; and resistance to sweat, wind, water, and temperature ${ }^{11}$.

Botanical extracts, such as clove, bergamot, andiroba, citronella, neem, and eucalyptus, are being explored as potential repellents for children and pregnant women, nevertheless having less efficacy than industrial ones ${ }^{8,12}$.

In our study, high concentrations of IR3535, as well as icaridin, resulted in more favorable repellent performance against $A$. aegypti bites than DEET and IR3535 at low concentrations associated with botanical extracts.

The variability of the volunteers' measurements reinforces the individual susceptibility to A. aegypti bites and subsidizes the need for comparative studies with paired analysis of the data for more consistent conclusions, as well as explaining the superior global performances of all repellents in certain subjects.

The results obtained in controlled experimental studies should not be extrapolated to clinical situations. The concentration of mosquitoes used ( 5 mosquitoes/liter of air), and the voracity promoted are higher than those found in nature. On the other hand, the hierarchy of protection time identified in the laboratory tends to remain between products in open clinical trials.

Likewise, periodic reapplication of less efficient repellents is a safe strategy to maintain protection ${ }^{11}$. For example, DEET at a concentration of $7.1 \%$ is recommended to be reapplied every 2 hours, which can compensate for protection as efficiently as icaridin or $30 \%$ IR3535 in a single application.

Finally, repellents should be understood as measures of individual protection, with the potential to reduce disease indicators if used correctly, and in adequate quantities. Efficient public policies, however, should not be based only on repellents, but on restricting the reproduction of vectors.
In conclusion, 25\% icaridin spray and 30\% IR3535 resulted in better performance among pediatric repellents tested against A. aegypti bites.

\section{Conflict of interest}

The authors declare that there is no conflict of interest.

\section{REFERENCES}

1. Moyes CL, Vontas J, Martins AJ, Ng LC, Koou SY, Dusfour I, et al. Contemporary status of insecticide resistance in the major Aedes vectors of arboviruses infecting humans. PLoS Negl Trop Dis. 2017;11(7):e0005625.

2. D'Alessandro U, Olaleye BO, Langerock P, Aikins MK, Thomson MC, Cham MK et al. Mortality and morbidity from malaria in Gambian children after introduction of an impregnated bednet programme. Lancet. 1995;345(8948):479-83.

3. Soto J, Medina F, Dember N, Berman J. Efficacy of permethrinimpregnated uniforms in the prevention of malaria and leishmaniasis in Colombian soldiers. Clin Infect Dis. 1995;21(3):599-602.

4. Schreck CE, Haile DG, Kline DL. The effectiveness of permethrin and deet, alone or in combination, for protection against Aedes taeniorhynchus. Am J Trop Med Hyg. 1984;33(4):725-30.

5. Stefani GP, Pastorino AC, Castro APBM, Fomin ABF, Jacob CMA. Repelentes de insetos: recomendações para uso em crianças. Rev Paul Pediatr. 2009;27(1):81-9.

6. Fradin MS. Mosquitoes and mosquito repellents: a clinician's guide. Ann Intern Med. 1998;128(11):931-40.

7. Islam J, Zaman K, Duarah S, Raju PS, Chattopadhyay P. Mosquito repellents: an insight into the chronological perspectives and novel discoveries. Acta Trop 2017;167:216-30.

8. Miot HA, Lauterbach GP, Ribeiro FAH, Favero Jr EL, Hercos GN, Madeira NG, et al. Comparison among homemade repellents made with cloves, picaridin, andiroba, and soybean oil against Aedes aegypti bites. Rev Soc Bras Med Trop. 2011;44(6):793-4.

9. Miot HA. Assessing normality of data in clinical and experimental trials. J Vasc Bras. 2017;16(2):88-91.

10. Miot HA, Batistella RF, Batista KA, Volpato DEC, Augusto LST, Madeira NG, et al. Comparative study of the topical effectiveness of the andiroba oil (Carapa guianensis) and DEET 50\% as repellent for Aedes sp. Rev Inst Med Trop Sao Paulo. 2004;46(5):253-6.

11. Brown M, Hebert AA. Insect repellents: an overview. J Am Acad Dermatol. 1997;36(2 Pt 1):243-9.

12. Das NG, Baruah I, Talukdar PK, Das SC. Evaluation of botanicals as repellents against mosquitoes. J Vector Borne Dis. 2003;40 (1-2):49-53. 